
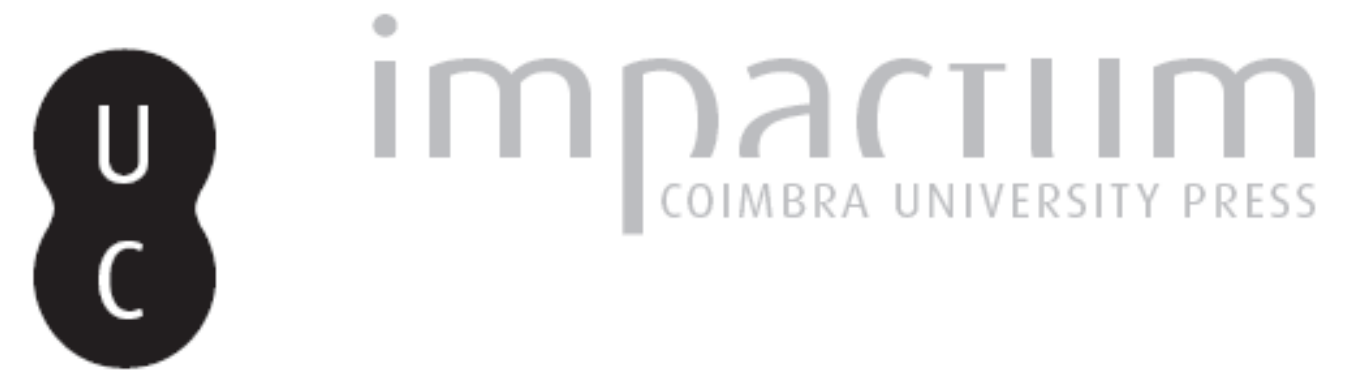

\title{
Escrivães e pregoeiros dos concelhos (séculos XIV-XVI)
}

Autor(es): $\quad$ Santos, Maria José Azevedo

Publicado por: Centro de História da Sociedade e da Cultura

URL persistente:

URI:http://hdl.handle.net/10316.2/39362

DOI:

DOI:http://dx.doi.org/10.14195/1645-2259_14_4

Accessed : $\quad$ 26-Apr-2023 12:21:47

A navegação consulta e descarregamento dos títulos inseridos nas Bibliotecas Digitais UC Digitalis, UC Pombalina e UC Impactum, pressupõem a aceitação plena e sem reservas dos Termos e Condições de Uso destas Bibliotecas Digitais, disponíveis em https://digitalis.uc.pt/pt-pt/termos.

Conforme exposto nos referidos Termos e Condições de Uso, o descarregamento de títulos de acesso restrito requer uma licença válida de autorização devendo o utilizador aceder ao(s) documento(s) a partir de um endereço de IP da instituição detentora da supramencionada licença.

Ao utilizador é apenas permitido o descarregamento para uso pessoal, pelo que o emprego do(s) título(s) descarregado(s) para outro fim, designadamente comercial, carece de autorização do respetivo autor ou editor da obra.

Na medida em que todas as obras da UC Digitalis se encontram protegidas pelo Código do Direito de Autor e Direitos Conexos e demais legislação aplicável, toda a cópia, parcial ou total, deste documento, nos casos em que é legalmente admitida, deverá conter ou fazer-se acompanhar por este aviso.

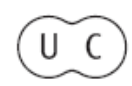




\section{4 \\ 2014}

\section{evista de História da Sociedade e da Cultura}

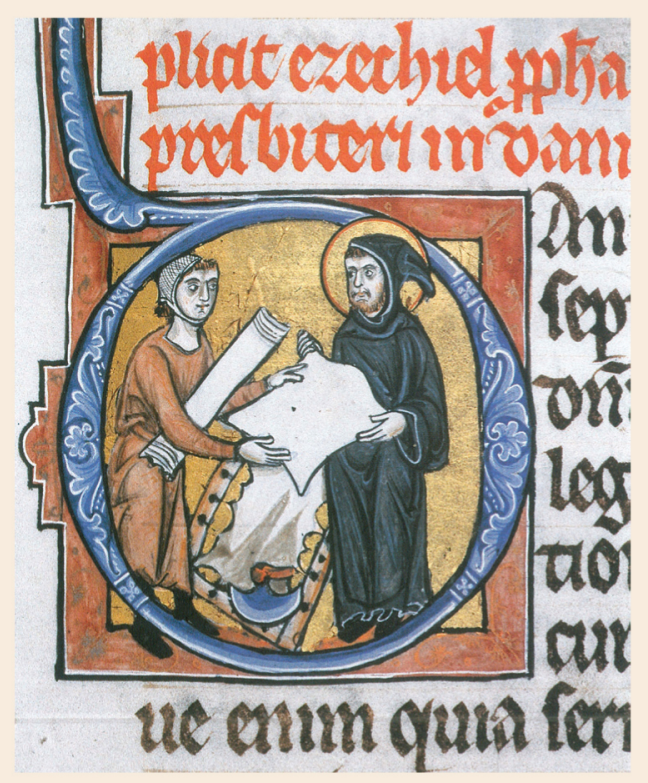

Centro de História da Sociedade e da Cultura Universidade de Coimbra 


\title{
Escrivães e pregoeiros dos concelhos (séculos XIV-XVI)
}

\author{
Maria José Azevedo Santos \\ UC - FLUC, Centro de História da Sociedade e da Cultura \\ mazevedo_santos@yahoo.com \\ Texto recebido em/Text submitted on: 10.05.2014 \\ Texto aprovado em/Text approved on: 24.10.2014
}

\section{Resumo/Abstract:}

$\mathrm{O}$ trabalho que se segue procura demonstrar, com o recurso a fontes de natureza diversa, a importância dos escrivães e dos pregoeiros nos governos concelhios do Reino de Portugal. A administração necessitava tanto da linguagem escrita como da oral para desenvolver, com eficácia, os encargos que lhes eram confiados.

The following study attempts to show, with resort to sources of a diverse nature, the importance of notaries and criers in the municipal governments of the Kingdom of Portugal. The local administration was in need of both written and spoken language to carry out in an effective manner the tasks that were assigned to it.

Palavras chave/Keywords:

Escrivães; Pregoeiros; Escrita; Poder local.

Notaries; Criers; Writing; Local government.

Trabalho apresentado na Tarde Cultural - Homens da História - de 25 de Fevereiro de 2014, no Arquivo Distrital de Aveiro, aquando da cessação de funções, como Directora da Senhora Dra. Maria Lucinda Bastos Tavares dos Santos. 


\section{Introdução}

A escrita, essa técnica inventada há milénios, responsável pela fronteira, ainda que empírica, que separa a Pré-História da História, é abordagem obrigatória para quem pretender, de algum modo, conhecer uma vila, uma cidade, uma instituição, seja no seu todo ou em parte. A tarefa não é fácil. Na verdade, falar de escrita é falar de uma abstracção que só existe enquanto é concretizada em caracteres que são "agarrados" à pedra, ao pergaminho, ao vidro, ao papel, à madeira e a tantos outros materiais suportes de escrita.

Por isto, e pelas múltiplas interrogações e dúvidas que tem posto ao longo dos séculos, multiplicaram-se, até hoje, tentativas de definição, regra geral ligadas à vantagem que possui face à oralidade, ou seja, a de fixar os acontecimentos e combater a "memória deslembrada" como escreveu D. Duarte. Em todo o caso, Levy-Strauss, recentemente falecido, resumia as interpelações da escrita dizendo que "a escrita é algo de estranho".

Pela minha parte, recorro a Santo Agostinho e permito-me parafraseá-lo em relação ao que se diz sobre o tempo "O que é o tempo?: Se não me perguntarem eu sei. Mas se me perguntarem já não sei.” Digo o mesmo para a escrita.

De todo o modo, há dados inquestionáveis. Como é sabido, a escrita é uma técnica que exige aprendizagem, mas não é vital para o ser humano embora se torne indispensável, pelo seu fim útil, probatório e jurídico, para a gestão e organização de uma sociedade (falemos de uma vila, cidade, igreja, hospital, misericórdia, confraria).

\section{Escrivães}

A presença, e o crescente número, de escrivães no governo municipa ${ }^{1}$ foi, sobretudo, a partir do século XIV, produto da organização concelhia consubstanciada, entre outros aspectos, na existência de edifícios próprios,

1 Refira-se a presença em algumas cidades do reino de Portugal de escrivão da câmara e escrivão do concelho. Podiam coincidir na mesma pessoa mas, em princípio, tinham tarefas diferentes. Sobre este assunto, veja-se Maria Helena da Cruz Coelho, "Considerações em torno das chancelarias municipais", in Olhares sobre a História - Estudos oferecidos a Iria Gonçalves, Lisboa, 2009, p. 165-172. 
as câmaras, onde, a partir de então, passa a reunir a assembleia dos homens bons e começam a formar-se todos os elementos indispensáveis à boa e autónoma gestão municipal (actas, registos, livros, selos, arquivo, chancelaria) ${ }^{2}$. Paralelamente, pelo número de escrivães de um concelho, podemos hoje medir, com outros dados, a prosperidade e a influência político-social e administrativa desse território.

Pelo que fica dito, não deve causar espanto que as mais antigas actas de vereação, até hoje conhecidas, datem dos séculos XIV-XV (provenientes do concelho de Loulé) $)^{3}$. Leiamos a acta da sessão de 26 de Março de 1408: "no paço do concelho da vila, reunidos a mor parte dos moradores com o corregedor para escolherem os juízes e vereadores procuradores do concelho, ficou estabelecido que fossem escritas pelos escrivães escrituras d'el rei e escrituras pruvicas que pertencessem à escrevaninha do concelho e da vereação". Mas o que era a escrivaninha? Trata-se de um órgão do governo, neste caso local, responsável pela expedição e recepção de todos os actos escritos e bem assim pela feitura dos livros de vereamento ${ }^{4}$. Na terminologia de documentos castelhanos corresponde ao "ministério de papeles"5.

Mas perguntemos: qual o perfil humano, a formação, as obrigações e responsabilidade dos também chamados "escrivães da câmara"? A legislação, a analogia com ofícios peninsulares e europeus, permitem-nos distinguir,

2 É sabido de todos que, antes da centúria de Trezentos, as reuniões em apreço eram realizadas ao ar livre. Os documentos falam-nos da "praça do concelho", dos claustros de uma igreja, ou até, de uma árvore (carvalho), como locais de concentração para a assembleia. (Cfr., História de Portugal, direcção de José Mattoso, ed. Estampa, vol. 2, Lisboa, 1993, p. 228).

3 Luís Miguel Duarte, Actas de Vereação de Loulé (séculos XIV-XV, Loulé, 1992. Da Câmara de Coimbra, o livro homólogo, designado por "Livro dos Acordos e Vereações", data de 1491 e é da pena do escrivão Pero Vaz. (Arquivo Histórico Municipal de Coimbra, Vereações, . $\left.^{\circ} 1,1491\right)$.

4 Cabe a este propósito referir que o termo escrivaninha também designava o conjunto de objectos e materiais indispensáveis à escrita: salva, onde poisavam os tinteiros, poeiros e, por vezes, penas em descanso próprio. Em 1617, lê-se num livro de Receita e despesa da Câmara de Coimbra: "consta mais pagar a Francisco de Seixas, ourives, três mil e oiteenta rs.de fazer e reformar os timteyros, salvas e poeyros de prata, que fez e reformou para a camera..." (AHMC/Receita e Despesa, 1617, fl. 93; cfr. Símbolos do poder municipal, O Arquivo, Catálogo, Coimbra, 2008, p. 20).

5 Cfr. Mariano García Ruipérez, Tipologia Documental municipal, Castilla-La Mancha, 2002. 
desde logo, as condições exigidas, por um lado, enquanto pessoas, por outro, enquanto profissionais.

Quanto à pessoa, é sabido que devia ser do género masculino, livre, leigo, e gozar de "boa fama e costumes". Do ponto de vista do ofício público, era-lhe requerido honradez, conhecimentos jurídicos e, naturalmente, aptidão para escrever. Recrutados entre a classe pequena/média, urbana, dava-se preferência "aos da terra", isto é, aos naturais e moradores no concelho onde o ofício era exercido.

Entre as obrigações dos escrivães municipais, contava-se a feitura das actas das reuniões do concelho, ou seja, cabia-lhes registar e descrever as coisas feitas e ditas, as arguições, as petições, os diálogos dos vereadores. Redigiam muitos documentos em nome do concelho ou de outras pessoas. Passavam cópias autenticadas, faziam registos, $\operatorname{traslados}^{6}$, e, como epílogo, tinham o encargo de proceder à expedição das escrituras. Por sua vez, cumpria ao chanceler da câmara apor os selos e guardar as matrizes ${ }^{7}$. Inicialmente, os escrivães das câmaras exerceriam o cargo sem termo certo. Todavia, nos fins do século XIV, os concelhos foram obrigados a escolhê-los ano a ano num evidente combate à falta de idoneidade que muitos demonstravam ${ }^{8}$.

É fácil, pois, entender que pelas mãos dos escrivães, e pela máquina das chancelarias das câmaras, passava uma parte assinalável do governo local e da organização do poder central.

Loulé, vila algarvia, cujas actas das vereações dos séculos XIV-XV são as mais antigas até hoje conhecidas e editadas, como atrás ficou dito, tornou-se mais próspera, política, económica e socialmente, pelo contributo decisivo dos seus escrivães .

${ }^{6}$ Cfr. Mariano Garcia Ruipérez, ob.cit., p. 69 e ss. Refira-se, entretanto, que Lopo Diaz, escrivão de Loulé, "tresladou uma carta e logo no mesmo dia a pregou na praça, no pelourinho por ser lugar público... "(Luís Miguel Duarte, ob.cit., p. 217). É muito simbólico este acto, pois, como afirma José Mattoso: "O pelourinho é também símbolo da colectividade e representação material da justiça nela praticada... Era junto dele que se executavam as sentenças do tribunal local", ob.cit., p. 227-228.

7 Sobre aspectos importantes da sigilografia municipal, veja-se Saul António Gomes, Introdução à Sigilografia Portuguesa. Guia de Estudo, 2. ${ }^{\text {a }}$ edição, FLUC, 2012, p. 107 e ss.

8 Cfr. Maria Helena da Cruz Coelho, "art. cit", p. 169. Diga-se, todavia, que os abusos continuaram como a seguir se pode verificar no município do Porto.

9 Cabe referir que os escrivães, enquanto profissionais da escrita, ligados a todos os sectores da governança, pública ou privada, eram, então, sinal maior do sobreemprego da 
Da pesquisa na fonte em apreço, contámos 22 escrivães, sem identificação nem determinativo, a par de cerca de quatro dezenas de oficiais do concelho, dos quais nos é dado conhecer os nomes respectivos: Vasco Fernandez, Afonso Miguez, Rui Diaz, Lopo Diaz, Vasco Afonso e outros. Paralelamente, surgem os escrivães da correição, das sisas, da coudelaria, da obra da Igreja de S. Clemente, da avaliação dos rendimentos dos moradores da vila.

Consultemos, agora, as vereações dos séculos XIV-XV da cidade do Porto, já publicadas, e logo concluiremos que o escrivão é figura omnipresente. Da Alfândega à Bolsa, dos Contos à Correição, dos Órfãos à Câmara do duque de Bragança, os escrivães estão "dentro" de todas as instituições e serviços. ${ }^{10}$ Por sua vez, na Câmara, entre 1390 e 1432 foram identificados nove: Afonso Rodrigues, Afonso Vasco de Calvos, Afonso Vaz, Álvaro Gil, Antonino Dinis, Gil Carneiro, João Gonçalves, Pedro Afonso Cubas e Vasco Martins. Entre todos, merecem destaque Vasco Martins, tabelião e escrivão da câmara, o mais antigo que se conhece, detentor do cargo durante mais de quatro anos ${ }^{11}$ e Álvaro Gil que ocupa o cargo de 1393 a 1410, ano em que é afastado por ordem do Rei. Com efeito, pode ler-se na vereação de 10 de Setembro de 1410 que Álvaro Gil é "escripvam da camara dessa cidade ha muito mais dos tres anos" e pelo Regimento régio "nom o terá mais". Deste modo, ficou decidido na sessão respectiva que seria substituído por Afonso Vasques de Calvos, criado do duque de Bragança ${ }^{12}$.

Se, entretanto, compulsarmos o acervo do Arquivo Histórico Municipal de Coimbra, no que à documentação concelhia diz respeito, encontramos,

escrita que se vinha impondo à desvalorização paulatina da oralidade (Cfr. Albert d'Haenens, Le texte trace de l'anteriorité scribale, Louvain-la-Neuve, 1990 e P. Zumthor, Parler du moyen âge, Paris, 1980, idem, La lettre et la voix, dans Magazine littéraire, n. ${ }^{\circ}$ 279, Janvier, 1988. Quem percorre a documentação medieval e moderna, conhece bem a expansão que os escrivães, e, entretanto, as escrivãs, adquirem junto de pessoas e instituições, leigas ou religiosas, públicas ou privadas, daquém e dalém mar. Citemos, por exemplo, os escrivães das abadessas ou abades, dos hospitais, das confrarias, dos tribunais, dos arcebispos, das caravelas, das feitorias, enfim as escrivãs das rainhas ou damas.

${ }^{10}$ Cfr. Índices em "Vereaçoens" (1431-1432), Livro I. Leitura, Índices e notas de João Alberto Machado e Luís Miguel Duarte, Câmara Municipal do Porto, 1985, p. 246-248.

11 "Vereacoens", anos de 1390-1395, o mais antigo dos Livros de Vereações do Município do Porto. Comentário e notas de A. de Magalhães Basto, Câmara Municipal do Porto, Porto, s. a., p. 11, 12, 14, 18-20 e outras.

${ }^{12}$ Ver "Vereaçoens", anos de 1401-1449, nota prévia de J. A. Pinto Ferreira, Câmara Municipal do Porto, Porto, 1980, p. 342-343. 
entre os séculos XV e XVII, escrivães que, pelo seu papel na produção e reprodução da memória do concelho conimbricense, há muito que pertencem à galeria das figuras notáveis da vida e da história da cidade. Demos como exemplo Pedro Afonso que, no século XV, usa, como data tópica nos actos que redige, Torre da Rolaçom, de Coimbra ${ }^{13}$. Da centúria seguinte, Nuno de Parada revela-se um escrivão de competente técnica e cultura gráfico-diplomática ${ }^{14}$. Em 1532, avaliza a organização do Inventário dos bens, rendas e foros do concelho, dito, o Tombo Antigo, da pena de Manuel Afonso. Nele é descrita a, entretanto, chamada Torre da Camara: "sobre a porta d'Almedina", onde "se fazia camara" e, em cima, se dizia missa justamente antes das reuniões ${ }^{15}$. Por sua vez, Inofre da Ponte deve o seu renome por um lado, à elaboração, quase integral, do $1 .{ }^{\circ}$ Livro da Correia, ou seja, o "Livro de Regimentos e Posturas", do século XVI, por outro, porque, anos depois, em 1526, num fenómeno, não raro, passa a integrar o conjunto dos vereadores da cidade ${ }^{16}$.

Já do século XVII, merece especial referência Simão de Moraes responsável pelo traslado do Livro de Posturas e correições da cidade de Coimbra que é composto de disposições camarárias desde 1404 até 1703. Tratou-se de dar cumprimento a uma determinação da câmara, datada de 22 de Julho de 1601, e onde podemos ler: “... foi dito a eles juis de fora, e vereadores que o livro das posturas desta cidade per que se governavão os almotaceis e condenavão a requerimento dos rendeiros, estava todo gastado pelo que hera necessário fazer outro de novo..." e que o dito Manoel Carreira, procurador corresse com isso a custa da dita cidade e se fizesse hum livro de pasta muito bom com as armas da dita cidade..."17.

${ }^{13}$ Arquivo Histórico Municipal de Coimbra, Pergaminhos Avulsos, n. ${ }^{\circ}$ 57. Cfr. Símbolos do poder municipal, ob.cit., p. 35-36.

${ }^{14}$ Ibidem.

${ }^{15}$ AHMC/Tombo antigo, 1532.

${ }^{16}$ Ibidem, Livro da Correia, n. ${ }^{\circ} 1$; Vereações, n. ${ }^{\circ} 5,1526$, fl. 1.

${ }^{17}$ Cfr. Símbolos do Poder Municipal, p. 38-39. Acrescente-se que trasladar, registar, encadernar foram práticas frequentes usadas pelos concelhos para salvaguardar e proteger o património documental. No século XVII, a Câmara de Abrantes "empreende um extraordinário labor de registos autênticos de escrituras respeitantes à sua administração, fazendo-os encadernar em livros, em papel, cobertos de couro, de grandes dimensões", veja-se Maria José Azevedo Santos, "Os concelhos e a conservação dos documentos: o caso de 
Os escrivães das câmaras, porém, cruzavam-se, com frequência, com os tabeliães ou notários públicos, que também serviam os concelhos, e com eles dividiam tarefas que, em comum, tinham a exigência da ars scribendi. É o caso da Câmara Municipal de Aveiro.

Consulte-se o Livro dos Acordos de 1580, aliás um ano nefasto para o reino de Portugal, e verificaremos que das 63 actas de vereação, de Janeiro a Setembro, 54 foram escritas pelo escrivão da Câmara, António da Fonseca, enquanto de nove se encarregaram quatro tabeliães da vila: Francisco Rodrigues, Afonso de Araújo, Vasco Ribeiro e Simão André18.

Importante é lembrar aqui, igualmente, o papel decisivo que os escrivães das câmaras e os tabeliães tiveram na "publicação" dos forais manuelinos dos respectivos concelhos, lendo-os, ou escrevendo-os, e servindo de testemunhas nos autos respectivos ${ }^{19}$. Eram todos, porém, considerados "artesãos" e apesar de a sua arte ser de indesmentível "utilidade pública", o comportamento transgressor e corrupto em que, com facilidade, caíam, sobretudo os tabeliães, gerava opiniões muito depreciativas a seu respeito. Escrever era, então, poder e este, ontem como hoje, corrompe.

Martin Perez, clérigo castelhano do século XIV, escreveu no seu conhecido Livro de las Confessiones: "Os escrivães desgraçadamente sabiam escrever" ${ }^{20}$. É notável o capítulo que lhes dedica intitulado "pecados, danos

Punhete", in Carta Régia de Punhete (Constância) 1571, Câmara Municipal de Constância, 2007, p. 15-18.

${ }^{18}$ Arquivo Distrital de Aveiro, cota 5. Cfr. Francisco Ferreira Neves, Livro dos Acordos da Câmara Municipal de Aveiro de 1580, ed. C. M. A., 1971.

${ }^{19}$ Citem-se, como exemplo, os forais de Vale de Cambra (Foral de Cambra, Fac-símile, Câmara Municipal de Cambra, 2004), de Jarmelo (Foral Manuelino de Jarmelo, estudo e transcrição de Maria Helena da Cruz Coelho e Maria do Rosário Morujão, Museu da Guarda/ Associação Cultural e Desportiva do Jarmelo, 2010, p. 88-89), de Ílhavo (O Foral Manuelino de Ílhavo, Introdução, transcrição e revisão científica de Saul António Gomes, Município de Ílhavo, 2009, p. 82), de Santarém (Foral de D. Manuel I a Santarém, estudo, transcrição e glossário de Maria Helena da Cruz Coelho, Câmara Municipal de Santarém, 2007, p. 296-297), de Mira (Foral de Mira 1514, edição facsimiliada e transcrição de Maria Alegria Fernandes Marques, Câmara Municipal de Mira, 2004) entre muitos outros.

${ }^{20}$ Cabe lembrar, igualmente, Castillo de Bovadilla que escreveu "dos ofícios hallo que han de ejercerse por hombres de buen linaje, uno el del boticário y outro el del escribano, porque el uno com la purga y el outro com la pluma matan callando" (Política para corregidores, L. III, cap. XIV, ed. Facsímil, Madrid, 1978. 
e enganos que cometem nos seus ofícios ${ }^{21}$. Apesar de tudo, nas cerimónias religiosas, especialmente na procissão do Corpo de Deus, em Coimbra ou em Évora, na Idade Média, é-lhes prestado público reconhecimento. Aí, encontramos escrivães do almoxarifado, escrivães da almotaçaria, escrivães dos órfãos, entre outros, prova, aliás, da multiplicidade das escrivaninhas dos concelhos e fruto da complexidade burocrática e consequente divisão de tarefas. Todos, com tochas acesas, ocupavam, no cortejo processional, hierarquicamente constituído, posição de destaque o mesmo é dizer desfilavam quase no fim da procissão separados da Hóstia Sagrada (no fecho) apenas por membros das camadas mais distintas da sociedade urbana (tabeliães, procuradores, juízes) ${ }^{22}$. O escrivão da câmara, em particular, era privilegiado pelos honorários que auferia. Por exemplo, em fins do século XVI, Miguel Tavares, da Câmara de Santarém, recebia, anualmente, de ordenado 12.000 reais e outro tanto de um moio de trigo, num total de 24.000 reais. Esta quantia era assinalável, pois representava 17,5\% da verba geral de 136.900 reais de ordenados pagos pela Câmara nesse ano de 1591. Com efeito, o tesoureiro, o relojoeiro, o solicitador ou até o "escrivão da câmara de Sua magestade" receberam salários muito inferiores ${ }^{23}$. Na verdade, o vínculo da escrita às sociedades dos séculos XV e XVI é, pois, de tal maneira forte, que podemos falar, sem exagero, de uma escribocracia. Tudo se escreve: leis, inventários, receitas e despesas, dívidas, actas, doações, quitações, perdões, legitimações. Por sua vez, homens e mulheres, alfabetizados ou não, experimentavam, uma vez que fosse, na vida, a necessidade de possuir um documento para vender uma casa, doar uma vinha, renunciar a um contrato, pedir ao Rei uma mercê.

Uma vez produzido o documento, autores e destinatários preocupavam-se, sobremaneira, com a sua guarda e conservação. A todo o tempo, podia ser necessário para reivindicar o direito de propriedade, para confirmar um privilégio, enfim para renovar um contrato. Em cenários litigiosos, a posse

${ }^{21}$ Martin Pérez, Livro das Confissões, partes I e II, ed. de José Barbosa Machado e Fernando Torres Moreira, ed. Pena Perfeita, 2005 e idem, partes III e IV, idem, 2006.

${ }^{22}$ Veja-se Maria João Violante Marques da Silva, "A procissão na cidade: reflexões em torno da festa do Corpo de Deus na Idade Média Portuguesa", in A cidade. Jornadas inter e pluridisciplinares, Lisboa, 1993.

${ }^{23}$ Veja-se Maria Ângela da Rocha Beirante, Santarém Quinhentista, Lisboa, 1981, p. 162 e 163. 
de documentos, pelas partes, ganhava um aparato "bélico", pois papéis e pergaminhos adquiriam a força, por vezes imbatível, de bestas ou lanças ${ }^{24}$. Por tudo isto, todas as instituições medievais, públicas ou privadas, leigas ou religiosas, revelaram grande preocupação com a guarda das suas escrituras, património de valor único e irreproduzível. Os hospitais, os mosteiros, as igrejas, as confrarias, ainda que de forma incipiente, recorreram a diversas formas para defender as escrituras, avulsas ou em livro, da destruição, ou desaparecimento, por malícia ou caso fortuito. Fácil é compreender que as câmaras, e os seus governantes, conscientes do valor dos escritos, tenham procurado, igualmente, acautelar livros, "papéis e pergaminhos" regulamentando a sua "curadoria" e salvaguarda ${ }^{25}$. Por exemplo, era comum existir, sobretudo nos concelhos maiores, uma ou mais arcas, de tamanhos vários mas de estrutura resistente para evitar furtos ou destruições. Encontramos ainda referência a outros móveis como uchas, cofres e, mais tarde, armários e bufetes ${ }^{26}$, cuja configuração vai respondendo quer ao género dos escritos a conservar (cartas avulsas ou livros) quer ao modo de arrumação e ordenamento dos documentos produzidos. Usada pela Câmara de Coimbra, ainda hoje é possível admirar uma arca, de ferro forjado, de pequenas dimensões, datável do século XVII e que decerto serviu para guardar algumas escrituras consideradas valiosas ${ }^{27}$. Entretanto, diga-se que da maior ou menor atenção dedicada à ordem dos cartórios concelhios, nos séculos passados, dependeu, em boa parte, o número e o estado de conservação do património arquivístico que chegou aos nossos dias e que as câmaras, nos seus Arquivos Históricos, procuram continuar a preservar ${ }^{28}$.

${ }^{24}$ Cfr. o meu livro, O valor da escrita em tempos de Inês de Castro, ed. Câmara Municipal de Montemor-o-Velho, 2005, p. 47 e 55.

${ }^{25}$ Veja-se da autora, "As condições de conservação dos documentos e dos livros em Portugal (séculos XII-XV)”, in Estudos de Diplomática Portuguesa, p. 233-256.

${ }^{26}$ Bufete é um vocábulo que provém do francês buffet e é já documentado no século XVII com o significado de mesa ou aparador para livros. Veja-se José Pedro Machado, Dicionário Etimológico da Língua Portuguesa, 3. a ed., Lisboa, 1977, vol. I, s.v. bufete.

${ }^{27}$ Museu Nacional Machado de Castro, n. ${ }^{\circ}$ 12947. Na pessoa da Sr. ${ }^{\text {a }}$ Directora, Dr. ${ }^{a}$ Ana Alcoforado, agradecemos a gentileza das informações.

${ }^{28}$ Veja-se sobre arquivos municipais, em especial o do Porto, Manuel Luís Real, Arquivos Municipais em Portugal: Porto, o sistema de Arquivos da Câmara Municipal do Porto, ADB/UM, Braga, 1996. 


\section{Pregoeiros}

Mas de que valeria escrever, produzir sentenças, cartas e posturas, se não fossem lidas, vistas e conhecidas por todos? Com efeito, num reino cuja população era, na sua quase totalidade, analfabeta, tornava-se fundamental anunciar o que era escrito, lançar pregões, convocar, etc. Falemos, então, dos pregoeiros ${ }^{29}$. Recrutados entre as camadas mais baixas da sociedade, peões, por exemplo, não lhes eram exigidos grandes dotes intelectuais ou culturais. $\mathrm{Na}$ verdade, até poderiam não saber escrever, pois o principal era saber ler, decorar e apregoar (sem recurso à leitura). Auferiam salários muito baixos, embora o ofício fosse de grande responsabilidade. No século XIV, na Câmara de Lisboa, todos os pregoeiros, por postura municipal, eram obrigados a jurar sobre os Santos Evangelhos que prometiam cumprir "bem e dereytamente seu ofizio". As prevaricações registadas contra o regulamento dos vários pregões, sujeitavam-nos à suspensão do cargo, do salário ou ao pagamento de $\operatorname{coimas}^{30}$. Homens do povo que, pelo fim útil do seu ofício, eram merecedores, em geral, da consideração da sociedade. A.H. de Oliveira Marques chama-lhes "funcionários públicos" e poe-os no grupo dos contadores, mordomos, almoxarifes e ouvidores ${ }^{31}$. Não raro surgem como testemunhas em cartas particulares. João de Arazede, pregoeiro do concelho de Montemor-o-Velho, foi testemunha numa carta datada de 28 de Março de 1338 que, além disso, deixou escrito que ele "disse e deu ffe que apregoara as ditas casas per três nove dias e muito mais pela dicta villa".

${ }^{29}$ Pregoeiro, de origem latina, é o vocábulo mais comum para identificar "aquele que lançava pregões". Todavia, excepcionalmente, aparece, de origem árabe, adel, plural adéés. Veja-se numa carta do concelho de Ponte de Lima, de 21 de Julho de 1383, a referência a Domingos Esteves adeel da dicta villa que apregoara o dicto conçelho segundo he de costume... (Cortes Portuguesas. Reinado de D. Fernando I (1367-1383), JNICT, Lisboa, vol. II, 1993, p. 275.

${ }^{30}$ Ver Posturas do Concelho de Lisboa (século XV), Sociedade Língua Portuguesa, Lisboa, 1974, p. 53. Situação idêntica acontecia noutras terras como Sacavém de que se conhece em 1356 Vicente Martins "pregoeiro jurado do concelho de Sacavém). Ver Documentos Medievais (1179-1383), Arquivo Municipal de Lisboa. Catálogo. Coordenação de Inês Morais Viegas e Miguel Martins, ed. Câmara Municipal de Lisboa, 2003, p. 89.

${ }^{31}$ A. H. de Oliveira Marques, A sociedade medieval portuguesa, Sá da Costa, Lisboa, 5. a ed., 1987, p. 149. 
Por sua vez, Lourenço Vicente, de Alenquer, foi testemunha numa carta de $1437^{32}$. Nas câmaras, ganhavam, sem dúvida, um papel decisivo no anúncio de toda a documentação que era forçoso dar a conhecer às gentes da terra.

O município do Porto é bem prova disso. Nas actas de vereação é frequente a referência aos pregoeiros que "lancarão pregão" para arrendamento de casas, para definição de pesos e medidas, para eleição de juízes e procuradores, para interdição da venda de vinhos em barcas, entre tantos outros $^{33}$. Foram arrolados mais de uma dezena entre 1390 e 1432. Muitos, a atestar a sua baixa condição social, ficaram para a história como o Geraldo, o Vasco, o Vicente, enquanto outros denunciam, no sobrenome, a sua proveniência geográfica: João de Arouca e João da Póvoa ${ }^{34}$.

$\mathrm{Na}$ verdade, nunca é demais dizer que a escrita, palavra sedentária, agarrada a um qualquer suporte, só cumpre a sua verdadeira missão quando volta a ser "nómada", ou seja, quando é lida e pode ser ouvida por muitos ouvidos e dita por muitas bocas. Além disso, os pregoeiros das câmaras, que algumas vezes eram os próprios porteiros, desempenhavam uma acção muito importante na convocatória para as reuniões de vereação. Nos capítulos de cortes do reinado de D. Fernando I (1367-1383), encontramos perto de meia centena destes oficiais, de Trancoso a Sintra, da Guarda a Évora, de Lisboa a Melgaço, passando por Penela, Soure, Lousã, Montemor-o-Velho. A todos coube essa missão de apregoar o "concelho" por mandado, regra geral, dos juízes ${ }^{35}$. Por sua vez, os vereadores podiam ordenar que o pregoeiro apregoasse "que todolos cavaleiros e escudeiros e piiões e beesteiros e cada hûm de seu mester veesse ao dito logo pera ovir hûa carta d'El Rey...”. Esta disposição, lia-se em carta de 1352, de 11 de Setembro,

${ }^{32}$ João Pedro Ferro, Alenquer Medieval (séculos XII-XV). Subsídios para o seu estudo, Cascais, 1996, p. 265.

${ }^{33}$ Ver índices em "Vereaçoens" 1431-1432, Livro 1. Leitura, Índices e Notas de João Alberto Machado e Luís Miguel Duarte, 1985, p. 258-259.

${ }^{34}$ Interessante é a nota que nos dá Maria João Oliveira e Silva (A escrita na catedral. A chancelaria episcopal do Porto na Idade Média, CITCEM, Lisboa, 2013, p. 288-290: "os homens do pregão) sobre o facto, não raro, de a mesma notícia ser apregoada por mais do que um pregoeiro. Para a reunião do concelho do Porto, de 24 de Junho de 1358, as testemunhas foram convocadas por quatro pregoeiros do que logo o tabelião deu fé: "os vy e ouvi apregoar.

${ }^{35}$ Cortes Portuguesas. Reinado de D. Fernando I (1367-1383), JNICT, Lisboa, vol. II, 1993. 
da Câmara de Lisboa ${ }^{36}$. Com voz "preparada" ou "entoada", regra geral em espaços movimentados, feiras, praças, mercados, chamavam o povo pelo toque de uma trombeta e, de seguida, proclamavam as notícias às gentes que, entretanto, se juntavam. Nas vereações de Loulé, já referidas, encontrámos alusão a nove pregoeiros, número significativo. Citem-se, em particular, Afonso Anes que escolheu a Torre da Porta da Vila, lugar donde a voz lhe sairia melhor, enquanto Afonso dos Asnos apregoou várias ordenações, perante o escrivão, "na praça da dicta vila". Por sua vez, Martim Afonso Pato e outros apregoaram o dia do concelho e nele deram fé que o haviam feito.

"Meter en pregom", tendas, chãos e sobrados para aforar, era ainda função dos pregoeiros das câmaras e de outras instituições como misericórdias e confrarias ${ }^{37}$.

Comum era, igualmente, apregoarem a venda de vinho, de carne, de azeite entre outros alimentos. As posturas municipais eram muito rigorosas relativamente a esta função. Por exemplo, o concelho de Lisboa determinou, no século XIV: "que os pregoeiros quando prometerem a alguém que apregoarem seu vynho que o nom apregoem a outrem ata que aquelle seja apregoado. E todolos pregoeiros que nom quiserem fazer os pregões assy como he sobredito nom seja pregoeyro por hum ano e pague LX soldos"38. Diga-se ainda que contratavam com os donos dos produtos o itinerário que deviam fazer estando, ainda, sujeitos aos horários que os concelhos estabeleciam.

A este propósito, refira-se um muito interessante documento de Lisboa, 1365, 28 de Novembro, pelo qual João Afonso, pregoeiro do concelho, atesta que apregoou pela cidade a postura, na referida data, que determinava o horário de venda de sardinhas e a prioridade que devia ser dada à venda de peixe fresco em detrimento do salgado ${ }^{39}$.

${ }^{36}$ Cortes Portuguesas. Reinado de D. Afonso IV (1325-1357), INIC, Lisboa, 1982, p. 137.

${ }^{37}$ Veja-se ainda o pregoeiro da corte que tinha atribuições muito especiais estabelecidas nas Ordenações Afonsinas (Ordenações Afonsinas, Livro I). Nota de apresentação de Mário Júlio de Almeida Costa. Nota textológica de E. Borges Nunes. F.C.G., Lisboa, p. 113.

${ }^{38}$ Posturas do concelho de Lisboa, p. 47, 48, 53.

${ }^{39}$ Documentos Medievais (1179-1383), Arquivo Municipal de Lisboa. Catálogo, idem, p. 106. 


\section{Conclusão}

Neste trabalho, ficou claro que a escrita, no seu fim útil de instrumento de gestão e administração local, possuía um poder único para vertebrar a vida quotidiana das gentes dos concelhos do reino de Portugal.

Ficou claro que essa técnica administrativa, nesses tempos, estava ao alcance de uma reduzida camada de escrevedores, profissionais, de que merecem destaque os escrivães e os tabeliães.

Ficou claro que era pela escrita que se legislava, taxava, sentenciava, castigava ou inocentava. Atente-se no número significativo de documentos: posturas, sentenças, cartas de isenção, cartas de foro, de arrendamento, de venda, de doação e tantas outras.

Mas ficou claro, sobretudo, que a escrita e o seu produto, os escritos só cumpriam a finalidade que lhes dava a existência se "saíssem" dos papéis e pergaminhos e voltassem a ser voz.

Concluindo, ficou claro que os governos concelhios necessitavam, tanto da linguagem escrita, e dos escrivães, como da linguagem oral, e dos pregoeiros, para desenvolverem completamente os encargos políticos, sociais e económicos que lhes eram confiados. 